\title{
La noción abstracta de propiedad en América: una visión desde los Andes ${ }^{1}$
}

Héctor Omar Noejovich

\section{Introducción}

Una de las características en América Latina en general, y de la región andina en particular, es el carácter difuso que toma el derecho de propiedad. Este carácter "difuso" hoy cobra particular importancia a la luz de los nuevos paradigmas del neo-institucionalismo. ${ }^{2}$

Según nuestras investigaciones, ${ }^{3}$ el problema debe analizarse desde la herencia precolombina y el choque que significó el «encuentro de dos mundos", a través de las modificaciones institucionales surgidas en el período colonial y su evolución en la etapa republicana, especialmente después de la reforma liberal de mediados del siglo XIX.

Como se sabe, la cuestión ha sido tratada frente con referencia a la dicotomía entre la ley y la costumbre; enfatizando sobre la problemática

1 Este trabajo deriva de la ponencia presentada en el XII Congreso Internacional de la Asociación de Historiadores Latinoamericanos Europeos, Oporto, Portugal, octubre de 1999.

2 Douglass North, Instituciones, cambio institucional y desempeño económico, FCE, México.

3 Héctor Omar Noejovich, «Las relaciones del Estado Peruano con la población indígena en el siglo XIX, a través de su legislación", en: Histórica, XV: 1, Fondo Editorial PUCP, Lima, 1991; Del mismo autor, "El régimen de bienes en la América precolombina y el hecho colonial», en: CISEPA N 107, PUCP, Lima, 1992-1993; asimismo, "L'Economie Andine et Mesoamericaine dans l'environnement de la Conquête Espagnole», Université de Lille III, ISSN: 0294-1767, Francia; también, «El pensamiento dual andino y sus implicaciones socioeconómicas", en: Histórica, XIX: 1, Lima, 1995; Los albores de la economía americana, Fondo Editorial PUCP, Lima, 1996; “Tierra e indios en México y Perú», en: Actas del «Simposium en Honor del Prof. Ruggiero Romano», México D.F., 1998. 
indígena ${ }^{4}$ o sobre el cumplimiento de la ley. ${ }^{5}$ La existencia de un sistema de iure frente a un sistema de facto, creo que excede a esa explicación y es un aspecto de las sociedades latinoamericanas que amerita otras argumentaciones y enfoques.

Este trabajo intenta establecer un marco analítico para reflexionar sobre esa evolución y esbozar las perspectivas futuras, teniendo como eje a la "propiedad", en sentido abstracto. La base documental proviene, principalmente, de la región andina y del Perú republicano, incluyendo algunos ejemplos actuales.

\section{La noción abstracta de propiedad}

¿Qué es la «propiedad»? Primera e importante cuestión. La interpretación usual, tanto en sentido corriente como jurídico, sugiere la idea de una categoría universal, inherente al ser; como si "naturalmente» todos los hombres, de todas las latitudes y culturas, tuvieran la idea de propiedad, con diferentes matices.

Nos encontramos entonces con la utilización amplia del vocablo, como una "etiqueta". En efecto, se habla de "propiedad comunal", "otro tipo de propiedad», un "derecho de uso en lugar de propiedad" y terminologías similares, para tipificar realidades difusas.

La confusión se suscita cuando esa "etiqueta» es entendida y/o utilizada como un "categorema», derivándose de ello un análisis en términos del derecho de propiedad. Así aparecen trabajos como los de Caso, ${ }^{6}$ que ubica el problema en la "conocida diferencia entre el dominio público y privado" para interpretar la civilización azteca o como el de Rostworowski ${ }^{7}$ sobre la propiedad de los incas, para citar algunos ejemplos de las múltiples confusiones que existen en la historiografía.

4 Rodolfo Stanvenhagen y Diego Iturralde (Comps.), Entre la ley y la costumbre: el derecho consetudinario indígena en América Latina, Instituto Indigenista Interamericano e Instituto Interamericano de Derecho Humanos, México, 1990.

5 Víctor Tau Anzoategul, La ley en América Hispana. Del Descubrimiento a la Emancipación, Academia Nacional de la Historia, Buenos Aires, 1992.

6 Alfonso Caso, "La tenencia de la tierra entre los antiguos mexicanos», en: Memoria del Colegio Nacional, IV: 2, México, 1959.

7 María Rostworowski, "Nuevos datos sobre tenencias de tierras reales en el incario", en: Revista del Museo Nacional, XXI, Lima, 1962. 
Los diversos "choques culturales», derivados de las aventuras coloniales decimonónicas, nos han nutrido de experiencias. En el África, se plantea la inexistencia de propiedad ${ }^{8}$ y el cuestionamiento de las categorías jurídicas utilizadas, ${ }^{9}$ para el caso de la India, frente a la pregunta: «¿el rey era el «propietario»?» se responde: «hacer esa pregunta es asumir que es propiedad y si uno no conoce qué se entiende por propiedad en la India, la pregunta es auto-frustrantem. ${ }^{10}$

El derecho de propiedad es esencialmente «individualista» en el sentido que debe existir un sujeto, que puede ser colectivo o individual y un objeto; de allí el meollo del problema. Es menester encontrar y definir quién es el dueño: rey, comunidad, Estado, inca, tlatoani, cacique, etc.

No se trata de establecer si hay propiedad privada y/o si ésta es individual o no. Esa conceptuación que gira alrededor del sujeto, asume axiomáticamente la existencia de un determinado "derecho real» de un "sujeto" sobre un "objeto", en el contexto de un marco institucional con un sistema jurídico predeterminado, partiendo de la posición del individuo. Gluckman ${ }^{11}$ arguye que constituye una falacia oponer «individualista" a "comunista" o "comunitario"; se está buscando siempre un "dueñon donde, probablemente, ese concepto carezca de sentido.

En un primer nivel, existen dos aspectos importantes de la "propiedad" que a mi juicio definen la existencia o inexistencia del derecho de propiedad en sentido abstracto: la alienabilidad y la condicionalidad, que enfocaremos desde la perspectiva de una sinopsis histórica. En un segun-

8 Land Tenure Symposium, Universitaire pers Leiden, [1940], Amsterdam, 1951.

9 Anthony Allott, "The ashanti law of property", en: Zeitschrift fur vergleichende, Stuttgart, 1966.

Xavier Blanc-Jouvan, "Les droits fonciers collectifs dans les coutumes malgaches", en: Revue Internationale de Droit Comparé, París, enero-marzo, 1964.

Raymond Verdier, "Les problemes de la propriété privée et collective chez les peuples primitives. Quelques remarques sur la propriété négro africaine», en: Etudes de Droit Contemporaine, París, 1958.

Raymond Verdier, "Chef de terre et Terre de lignage. Contribution a l'etude des systèmes de droit foncier négro-africaine», en: Etudes de Droit Africain et de Droit Malgache, París, 1965.

Duncan Derrett, "The devolpment of the concept of property in India", en: Zeitschrift fuir vergleichende Rechtswissenshaft, Stuttgart, 1962.

10 Héctor Omar Noejovich, «El pensamiento dual [...]», op. cit, p. 253.

11 Max Gluckman, Politics, Law and Ritual in Tribal Society, Backwell, Londres, 1965. Ver también la edición en español en Akal (Ed.), Madrid, 1978. 
do nivel, aceptada su existencia en un contexto social determinado, se refiere a la categorización en sí misma y es el concepto del desmembramiento de la propiedad. ${ }^{12}$ De hecho, el derecho de propiedad no es una categoría universal, sino un producto de la civilización occidental que sufrió un largo y complejo proceso de evolución.

El primer problema, la alienabilidad o inalienabilidad de la propiedad de la tierra, esclavos y siervos, ${ }^{13}$ se vincula con los modos de adquisición y su sentido en una sociedad determinada; las restricciones o prohibiciones para la venta u otras formas de transmisión, alteran las formas de acceso a esos bienes.

En las sociedades agrarias, el acceso a tierras está conectado con las concepciones religiosas y/o míticas. En el Antiguo Testamento (Levítico, 25:23) se señala: «Y la tierra no será vendida a perpetuidad porque vosotros sois en lo mío peregrinos y extranjeros", agregándose el "rescate» de tierras y siervos, que hubieran sido pignorados, mediante la institución del año jubilar (Levítico, 25: 8-22). Para el mundo mesopotámico, la transmisión de la tierra estaba "condicionada" a las funciones del cedente y del cesionario. ${ }^{14}$

Para la sociedad griega la propiedad era un atributo familiar, como una continuación entre el mundo de los vivos y el mundo de los muertos, donde los primeros solo tenían un derecho de goce sobre algo que pertenecía a un ente trascendente, a un ancestro familiar. ${ }^{15}$ Las reformas de Solón mostraron la intención de preservar la propiedad frente a la amenaza que representaba la acumulación. ${ }^{16}$ Los contratos de compra-venta

$12 \mathrm{O}$, con mayor precisión teórica, el desmembramiento del derecho de propiedad (cfr. Nicolini, 1958)

13 Los factores de producción general.

14 Szletcher (1963) señala la inexistencia, en el derecho arcadio-sumerio, de una palabra traducible como derecho de propiedad, en sentido abstracto. Indica una relación con la tierra independientemente de la categorización jurídica. No se puede precisar el "título del poseedor"; es indistinto ser "dueño", «arrendatario", "usufructario" 0 "depositario». En suma, no existía la posibilidad de «comercialización» de la tierra, aun cuando las restricciones no tenían un fundamento religioso, sino más bien, de protección a las situaciones estamentales.

15 Albert Farhat, "Le concept de propriété (Histoire du droit))» Academie International de droit comparé, VTeme. Congrès International, 1962.

$16 \mathrm{Al}$ condonar los gravámenes, representados por las horoi (monolitos que se colocaban en las propiedades para indicar las cargas que pesaban sobre ellas). 
sobre las propiedades agrícolas eran escasos. ${ }^{17}$ Resulta así una condicionalidad de la alienabilidad que restringe la noción abstracta de propiedad, al menos en el campo inmobiliario. ${ }^{18}$

Esa condicionalidad, llevada al extremo, convierte a la propiedad en inalienable y carente de todo sentido patrimonial. Si el conjunto de restricciones que pesan sobre la capacidad de alienar o disponer del bien, aunado a las condiciones establecidas para su goce, son de gran magnitud y complejidad, la categoría "propiedad» carece de sentido. Cuando esto sucede, el derecho de propiedad es inexistente.

También en la sociedad romana, existió una condicionalidad restrictiva de la alienabilidad. Aquello que denominamos derecho de propiedad, en la Roma arcaica era más bien el poder del pater familias omnímodo, ejercitado en función del grupo familiar sobre las cosas, personas y esclavos que les eran sujetos. Como consecuencia, la transmisión hereditaria no era meramente una cuestión económica, sino religiosa, respecto de las divinidades familiares. ${ }^{19}$

La evolución institucional romana, a partir de la Ley de las XII Tablas, solucionó el problema distinguiendo entre quiritarios y bonitarios, manteniendo los primeros las tradiciones en los modos de transmisión. ${ }^{20} \mathrm{El}$ elemento "parental» fue desapareciendo, siendo más relevante las "cosas o bienes"; esto finalmente devino en el concepto de patrimonio, como suma y resta de los distintos derechos y obligaciones del individuo.

«Así, nacido con limitaciones de status, referido a condiciones de ciudadanía y culto doméstico, el derecho de propiedad romano, por efecto de la expansión del Imperio, se convierte en un derecho des-

17 M. Finley, "L'alienabilité de la terre dans la Grèce ancienne», en: Annales, 25, París, 1970 .

18 La propiedad inmobiliaria era más un atributo de la persona y no un "activo» en sentido patrimonial. En el Ática, el derecho para disponer de la tierra era un privilegio exclusivo de los ciudadanos. Toda comunidad griega, en la época clásica era, para comenzar, una comunidad de propietarios de tierras y, en numerosos estados griegos, los derechos cívicos dependían, a su vez, de la propiedad inmobiliaria. Michael Austin y Pierre VidalNaquet, Economie et sociétés dans la Gréce ancienne, Colin, París, 1972, p. 111 y ss.)

19 Alberto Burdese, Manuale de diritto Privato Romano, Utet, Torino, 1975.

20 El quirites del ciudadano romano, en el que estaba imbricada la connotación religiosa familiar, requería de formas ceremoniales para transmitir la propiedad como la mancipatio y la iure cessio. Esta distinción se hace inocua a partir del Edicto de Caracalla en 212 p. $C$.. que concede la ciudadanía a todos los habitantes del Imperio. 
prendido de los atributos de su titular y transmisible sin restricciones de tipo personal o divino. Se impersonaliza respecto de la concepción "parental" que tenía desde antiguo." ${ }^{21}$

La conclusión de esta evolución histórica de la institución denominada "propiedad", se materializa en el Derecho justiniano, piedra fundamental de la categorización del derecho de propiedad en la sociedad grecoromana-judeo-cristiana.

El derecho de propiedad tiene su propia especificidad y es la proveniente de esa evolución histórica; cuando, por ejemplo, decimos que «no había propiedad sino un derecho de uso o una posesión», estamos incurriendo en una falsa categorización, toda vez que tanto el «derecho de uso como la posesión" son elementos integrantes del derecho de propiedad, al cual estaríamos desmembrando dejando sin definir los otros elementos. ${ }^{22}$ Si un sistema jurídico puede adecuarse a esta fórmula, implica la existencia del derecho de propiedad. En caso contrario, la noción abstracta de propiedad es inexistente y es menester una categorización diferente. Como señalara al comienzo de esta sección, debemos diferenciar entre «etiquetar»y «categorizar».

\section{La América precolombina}

Nuestra posición niega la existencia de una noción abstracta de propiedad en la América precolombina. ${ }^{23}$ Veamos nuestros argumentos comenzando por el señalamiento de tierras; ¡en qué consistía?.

Tomemos, por ejemplo el Testimonio de Martín Cari, mallku de Chucuito:

"Todas las tierras están repartidas entre los indios y cada uno tiene señalado lo que es suyo[...]». ${ }^{24}$

21 Héctor Omar Noejovich, Los albores [...], op. cit, p. 258.

22 El derecho de propiedad se desmembra en el jus abutendi, el jus fruendi y el jus utendi; la posesión se entiende como una posessio animus domini. Todos estos elementos son parte de un mismo conjunto.

23 Héctor Omar Noejovich, «El régimen de bienes[...], op. cit. y Los albores [...], op. cit.

24 Héctor Omar Noejovich, «El régimen de bienes[...], op. cit. y Los albores [...], op. cit. 
Por su parte, el otro mallku, Martín Cusi, añadía:

«[...] los indios tienen sus tierras y chacaras señaladas [...] al morir algún indio que no deja hijos [...] parte de las tierras a su mujer y las demás reparte entre los indios del ayllo donde era el indio [...] y si el dicho difunto no deja heredero se reparten todas las tierras entre su ayllo $\left[\ldots . . .{ }^{25} .{ }^{25}\right.$

El señalamiento no era ni vender, ni donar, ni arrendar, ni ceder; es simplemente una mera asignación transitoria del recurso. ${ }^{26} \mathrm{El}$ indio podía utilizar la parcela, mientras tuviese mujer e hijos; en caso de no tener ni cónyuge, ni descendientes, revertía al ayllu a su muerte.

Frente a las hipótesis sobre un derecho de uso, los siguientes testimonios denotan una asignación del producto de las tierras:

"[...] y que el ynga no tenia tierras suyas en este repartimiento mas de que ellos de las suyas sembraban para coger el maíz que le daban $[\ldots] \gg .{ }^{27}$

"[...] y hacían chacaras de maíz y coca y las de ají y papas [...] cuando se lo mandaban a estas tierras en que hacian dichas chacaras eran suyas de ellos y no del inga[...]» (Juan Xulcar de Auqimarca). ${ }^{28}$ «[...] tributaban por razón de las personas que eran y no por las tierras porque por ellas no les dieron ni daban ninguna cosa en reconocimiento de habérselas dado [...]» (Gaspar Cayua). ${ }^{29}$

Ello nos conduce a una primera conclusión:

"El llamado "tributo" tenía relación con las parcelas; además, la famosa «tierra del inca» era, más bien, un señalamiento de determinadas parcelas - "hacían chácaras"-, cuyos productos iban destina-

$25 \mathrm{Ibid}, \mathrm{p} .35$

26 Uso el vocablo asignar, en tanto implica una toma de decisión en materia económica y en cuanto a la organización de la producción.

27 Iñigo Ortiz de Zúniga, Visita de la provincia de Huánuco en 1952, John V. Murra (ed.), Universidad Herminio Valdizán, Huánuco, p. 39

28 Ibid, p. 47.

$29 \mathrm{Ibid}$, p. 47. 
dos al inca. No existía una tenancy ${ }^{30}$ que obligara a "pago" alguno; las prestaciones rotativas se sustentaban en el entrecruzamiento de derechos que generaban el juego de dones y contradones $y$, por supuesto, los vínculos de parentescom. ${ }^{31}$

El problema de la titularidad, característica del derecho de propiedad, fue una verdadera obsesión para los funcionarios españoles. Veamos algunas de las Instrucciones del Dr. Cuenca. ${ }^{32}$

"Ytem porque los dichos casiques sin tener poder para ello venden por su autoridad las tierras del repartimiento por suyas siendo de la comunidad» (ib: 141).

"Ytem porque las tierras e aguas de los repartimientos son de la comunidad de los indios y no del cacique ni principalesm. ${ }^{33}$

Matienzo ${ }^{34}$ planteó el problema con claridad, como doscientos cincuenta años más tarde insistiría Bolívar - cf. Infra - enfatizando sobre la posición del cacique, que «autoritariamente repartía las tierras»:

«[...] a cada uno en particular debe darse tantos topos que sepa y entienda que son suyas y que nadies se las ha de poder quitar ni tomar [...]" "[...] porque hasta aquí no han poseído tierras propias antes el cacique se las reparte como él quierem. ${ }^{35}$

Tenemos entonces una segunda conclusión para estos testimonios:

«Del párrafo resulta claro que: (a) la propiedad era un concepto y un derecho inexistente entre los indios; (b) no se menciona una "propiedad comunitaria" - como lo hace el Dr. Cuenca-, sino un siste-

30 En el sentido del common law.

31 Héctor Omar Noejovich, Los albores [...], op. cit, p. 292. Gregorio González de Cuenca, "Ordenanzas de indios" citado por María Rostworowski, "Algunos comentarios hechos a la ordenanza del Dr. Cuenca", en : Historia y cultura, 9, Lima, p.141.

32 Juan Matienzo, Gobierno del Perú, Institut francais d'études andines, París-Lima, 1967 , p. 57.

33 Ibid, p. 142.

34 Juan Matienzo, Gobierno[...], op. cit.

$35 \mathrm{Ibid}$, p. 57. 
ma donde el jefe étnico distribuye las tierras a su antojo; (c) la conclusión del Oidor era que se debía enseñar a los indios en qué consistía el derecho de propiedad». ${ }^{36}$

Polo $^{37}$ cita la «carencia de propiedad entre los indios», haciendo hincapié en las limitaciones para la disposición y obtención de tierras. Su mención sobre "merced del inca", en tanto vía de acceso, ${ }^{38}$ esto parece, más bien, un intento jurídico de justificar las "mercedes reales", en mérito a una continuidad de los usos y costumbres.

\section{Planteamos aquí una tercera conclusión:}

«Si los indios no tenían "propiedad» de la tierra y tampoco la tenía el Inca, ya que aquellos "no tributaban por el uso o goce del suelo", ¿qué sentido tiene establecer quién era el «dueño»? Francamente, ninguno. Los jefes étnicos, por su parte, si bien asignaban tierras, tampoco eran "dueños", siendo su función la distribución de las mismas y la solución de las disputas». ${ }^{39}$

De otro lado, la discontinuidad territorial del ayllu, fundamentado en el control de diversas ecologías, ${ }^{40}$ deviene en un damero territorial para

36 Héctor Omar Noejovich, Los albores [...], op. cit, p. 293.

37 Polo de Ondegardo, Relación de los fundamentos acerca del notable daño que resulta no guardar a los indios sus fueros, Urteaga y Romero (Eds.), 1916/17,3, 1916, p. 73.

38 Polo de Ondegardo, «Informe del licenciado Polo de Ondegardo al licenciado Briviesca de Muñatones", en: Revista Histórica, N 18, Lima, 1940, p. 142.

39 En 1876, ante disputas al interior de las comunidades, en la zona del Cuzco, el Poder Ejecutivo ordenó a los Prefectos abstenerse de intervenir como "árbitros y jueces» en ese tipo de conflictos, dejando su dirimencia al Poder Judicial. Con claro sentido moderno, se pretendió terminar con una práctica ancestral, donde los Prefectos habían ocupado la función de jefes étnicos (Héctor Omar Noejovich, "Las relaciones del [...], op. cit.). También resulta ilustrativo el ejemplo de las estancias Pototaca y Chillagua, donadas por los indios a los Jesuitas en la segunda mitad del siglo XVI y reclamada a la Junta de Temporalidades, luego de la expulsión de éstos dos siglos después (Ana María Presta, "Hacienda y comunidad. Un estudio en la provincia de Pilaya y Paspaya. Siglos XVIXVII», en: Andes, $N^{\circ} 1$, Salta, 1990). El razonamiento es claro de acuerdo al marco teórico presentado aquí: los indios les dieron la tierra a los jesuitas en reconocimiento; como los religiosos se fueron, las tierras debían revertir al ayllu. Héctor Omar Noejovich, Los albores [...], op. cit, p. 294. 
cada etnia. Esta discontinuidad territorial imposibilita un sistema de "propiedad" por métodos pacíficos, obligando a una convivencia donde "no existen dueños". La perdurabilidad del sistema -anterior al Tawantinsuyu, ${ }^{41}$ conduce a preguntarnos: ¿cómo funcionaba una sociedad sin "propiedad»?

Se trataba de una sociedad agraria, en la cual el principal recurso era la tierra y las categorías tales como dominio, tenencia, posesión, usufructo y otras similares carecían de significado para su interpretación. La función de los jefes étnicos, los horizontes culturales, la estructura de las obligaciones personales entre los grupos, respecto de la organización jerárquica y, muy especialmente, los vínculos de parentesco al interior de la etnia, fueron los elementos relevantes para el acceso a los recursos. El vínculo de parentesco es la sustentación del derecho andino. El derecho a tierras de los individuos, es ancestral en los Andes ${ }^{42}$ y subsiste en la actualidad. ${ }^{43} \mathrm{El}$ derecho a tierra para el sustento es una condición inherente al ser humano; la tierra es su pariente. Aquel que no tiene tierra es un wakcha, o sea un huérfano.

Esa concepción de "parentesco" o "ligamen" con la tierra no es exclusiva del mundo andino. ${ }^{44} \mathrm{El}$ parentesco del individuo con la tierra se produce en el marco del ayllu. Es al interior del mismo, en el marco de la discontinuidad territorial, donde ocurren las asignaciones de tierra mediante una redistribución periódica de las mismas. ${ }^{45}$

40 John Murra, "El control vertical de un máximo de pisos ecológicos en las sociedades andinas", en: Iñigo Ortiz de Zúñiga, Visita de la provincia de León Huánuco en 1562, 1967.

41 El desconocimiento de los españoles llevó a fragmentar, vía la dación de encomiendas, un ordenamiento propio de la estructura del sistema. Hay documentados casos de kurakuna que pleitearon tierras e, incluso, las compraron con el solo propósito de recomponer el «habitat» de la etnia de la cual se sentían responsables, en cumplimiento de su función (Franklin Pease, Relaciones entre los grupos étnicos de la sierra del sur y la costa: continuidades y cambios, 1982).

42 Felipe Guamán Poma de Ayala, Nueva coronica y buen gobierno, John V. Murra, (Ed.), Siglo XXI, México, 1980, p.1136.

43 José María Arguedas y Alejandro Ortiz Rescaniere, «La posesión de la tierra, los mitos prehispánicos y la visión del universo en la población monolingüe quechua» en: Les problemes agraires des ameriques latines, CNRS, París, 1965.

44 En el África la tierra pertenece a los samanfos, o sea a los espíritus. Para el caso de Madagascar existe un proverbio: "La terre, femme du Createur, nurrit les vivants" (René Rarijaona, Le concept de propriété en Droit Foncier de Madagascar, París, 1967) (La tierra, mujer del Creador, alimenta a los vivientes). El carácter parental es asaz evidente.

45 Necesarias, por otra parte, en la agricultura de secano. 
Los individuos se ligan al espacio y al tiempo, regulando sus relaciones personales de intercambio, tales como la minka, el ayni y la mita. Quien no pertenece al ayllu no tiene acceso a tierra, no forma parte de la red de prestaciones y se encuentra excluido de la sociedad andina. De esta forma el carácter restrictivo del derecho de propiedad, se encuentra desplazado hacia el derecho nacido del vínculo de parentesco. "No existe "derecho a los bienes", sino "derecho de pertenencia al ayllu"; no reivindico bienes, sino reclamo a mis parientes". ${ }^{46}$

Según Murra, ${ }^{47}$ en referencia a América precolombina,

"[...] en tales civilizaciones los derechos a la tierra estaban imbricados en la estructura política y social, que hablar de ellos en términos enteramente económicos es ineficiente para una futura investigación".

La creación de vínculos de parentesco era un instrumento de expansión:

"[...] vino por estos llanos un ynga [...] que venía por su bien [...] que no quería su plata ni el oro ni sus hijas [...] que lo reconociesen como señor [...] y asy les dio ropa que traya del Cuzco [...] después de ydo le hicieron una casa [...] le señalaron mugeres y yanaconas y chacaras" "[...] y el principal remedio que tenían pa bebir en paz era darse mugeres los unos a los otros». ${ }^{48}$

La creación es «doble»: al «darse mujeres» se reforzaban los vínculos de parentesco y al venir el Inca con regalos — ropa, en este caso—, se iniciaba una relación personal de reciprocidad que culminaba con «señalar chácaras y mujeres». Partiendo de la inalienabilidad de la tierra, la pregunta que sigue es: ¿qué pasaba con la herencia? ${ }^{39} \mathrm{Cusi}^{50}$ menciona como era la

46 Héctor Omar Noejovich, Los albores [...], op. cit, p. 296.

47 John Murra, «Derecho de acceso a tierras en el Tawantinsuyu», en: Revista de la Universidad Complutense de Madrid, N XXVIII: 117, 1980, p. 275.

48 Cristóbal de Castro y Diego de Ortega Morejón, «La relación de Chincha»; Juan Carlos Crespo (Ed.), en: Historia y Cultura N 8, [1558], Lima, 1974, p. 93.

49 La transmisibilidad indígena se caracterizaba por el carácter «generacional», a nivel de «hermano"; la sucesión en el mando era electiva, ajena al concepto de primogenitura (María Rostworowski, Estructuras andinas del Poder, IEP, Lima, 1982, p. 109). Así, la "herencia" no tenía un significado de "continuidad patrimonial", sino de "continuidad de metas a cumplir". Había que asegurar que el recurso cumpliera su función.

50 Cfr. Supra. 
transmisión de las parcelas y su eventual reversión al ayllu. ¿Cómo tipificar esa transmisión y su posterior reversión?

No se puede ceder o transmitir mejor derecho que el poseído. Ergo, este consistía en el derecho a sustentarse de la parcela, conforme al tamaño de la familia y a la calidad del terreno. Era una detentación condicionada y temporaria, ${ }^{51}$ restringida al tamaño de la familia y a la calidad del terreno, con la meta de la subsistencia, mientras la familia existiese. Si esta desaparecía, la parcela era susceptible de reasignación, continuando el proceso.

La discontinuidad territorial del ayllu y las reasignaciones periódicas muestran claramente el funcionamiento de este sistema. Una misma familia disfrutaba de distintas parcelas, no siempre la misma, a lo largo del tiempo, y de generación en generación, desconociéndose la figura de «heredad familiary. ${ }^{52}$

La exteriorización de una relación personal requiere de un espacio. Sea una prestación rotativa como la mita, sea un ayni prestado a un vecino, siempre existe un espacio donde se realiza. De esta forma existe una vinculación entre el espacio u objeto y la prestación en sí; a esto lo denomino un doble condicionamiento entre las relaciones personales y las relaciones reales. La meta es el imbricante de ambas.

La asignación periódica de tierras mostraba una relación de objetivos o señalamiento de metas, que en definitiva fijaban el destino de la relación entre los individuos y la tierra. El señalamiento de tierras muestra la funcionalidad en la asignación de recursos..$^{53}$ Cuando apreciamos «[...] señalar tierra para [...]», se está asignando el recurso y el destino de frutos que,

51 Héctor Omar Noejovich, Los albores [...], op .cit, p. 277.

52 Es obvio que los españoles dieron una interpretación formal a la «herencia indígena", a fin de permitir a la Corona la "reasignación» de los bienes "vacantes y mostrencos" (cfr. Solórzano y Pereyra, Política indiana, 1972).

$53 \mathrm{La}$ figura de «heredad familiar» tiene diversas aproximaciones. F. H. Lawson, «Family property and individual property". Vème. Congrès International de Droit Comparé, Bruxellles, 1967, discutiendo sobre family property versus individual property, señala la inconveniencia de aplicar criterios modernos, ya que la «heredad familiar" tenía distinto sentido para el campesino en la antigüedad. ¿Para qué iba a vender su «heredad"? En el caso de Madagascar, durante la ocupación francesa es semejante al nuestro. Ellos trataron de determinar la «heredad familian, para reivindicar a favor del Estado las tierras no ocupadas; ese fue el punto de choque entre los derechos tradicionales y el derecho de los invasores, cuando éstos intentaron establecer un catastro (cfr. Blanc-Jouvan). 
al mismo tiempo, es el objetivo de las relaciones personales; eso que denominamos meta establece la relación tierra-gente y los comportamientos.

Estamos ante un mutuo y recíproco condicionamiento, entre las relaciones personales y las relaciones reales. Tenemos nuestra cuarta conclusión:
"Así, la llamada «tierra del Inca" existe si, y solo sí, al mismo tiempo, existen las prestaciones rotativas efectuadas por los individuos; y vi- ceversa, las mitas existen si, y solo sí, al mismo tiempo existen tierras señaladas para ello». Es decir, que la especificación del objetivo - producción para el Estado suministrando este la subsistencia-, que categorizamos como meta, da contenido a las relaciones. La meta, en sí, no sustenta el derecho de acceso a la tierra, ni la obligación de la prestación; es el vínculo de parentesco el motor del proceso y la meta, el vehículo observable. ${ }^{54}$

En general las crónicas y testimonios indican en forma simultánea el bien - tierra, ganado o lana - y "para qué está destinado", de tal manera que las cosas no tienen existencia propia independiente de su utilización. Como si las cosas careciesen de sentido en sí mismas. ${ }^{55}$

La asignación de recursos, según sus metas, era una atribución de los jefes étnicos, en el contexto de una jerarquía vertical. Como se vio líneas más arriba, autores como Matienzo y Cuenca enfatizan la autoridad de los kurakakuna. Con referencia a la tierra, el urepartirlas como ellos quieren» reafirma esa autoridad, pero el problema está cuando se indica que "la venden como cosa propia». Eso es, a mi modo de ver, una confusión entre actos de administración y actos de disposición. Las denominadas tierras "de todos», «del común», eran administradas por los jefes étnicos, como una suerte de acervo del ayllu. ${ }^{56} \mathrm{Y}$ estas constituyen nuestra quinta conclusión de este desarrollo:

54 Ver.Guamán Poma en la enumeración de las distintas sementeras y Juan de Betanzos, [1551] Suma y narración de los incas, Lima, 1924, p. 149 y ss), en la descripción de las reformas de Pachacutec.

55 Héctor Omar Noejovich, Los albores [...], op. cit., p. 300.

56 El lápiz es lápiz mientras escribe. 
«En cuanto a las "mercedes del Inca", ${ }^{57}$ que mencionaba Polo, ${ }^{58}$ existen autores que la interpretan como una "propiedad privada". 59 Sin embargo, la detentación por parte de los beneficiarios no era muy diferente al resto del Tawantinsuyu; no podían venderla, ni comercializar sus frutos».

«El goce o disfrute consistía en disponer de tiempo para otras actividades, como la guerra, la administración de recursos y demás funciones dentro de la organización jerárquica; por tanto, esa detentación estaba condicionada por la función, mientras hubiesen herederos aptos para cumplirla. Este sistema permitía ampliar, a través de la jerarquía de mando, nuevas formas de reciprocidad y redistribución a diferentes niveles, que a la postre representaban una suerte de "progreso"”.

La detentación condicionada y temporaria, parece ser una tipificación adecuada y que sustituye a la noción abstracta de propiedad, como lo confirmaría la siguiente cita de Polo de Ondegardo. ${ }^{60}$

«[...] tampoco dividían los herederos $n y$ podían disponer de ella de ninguna manera (la tierra)».

"[...] se divide e dividía entre todos, conforme a la gente que cada uno tiene para sembrar e para comer; de manera que si tiene mas de una muger, danle mas tierra y conforme a la cantidad de hijos [...]" «[...] no le dan mas que lo que tienen entendido han de menester $[\ldots] . "$

57 «La tierra del linaje es la unidad jurídica que detenta los derechos inmobiliarios dinásticos, en cuyo centro se nuclean el conjunto de derechos ejercidos por sus miembros, organizados en una jerarquía de derecho-habientes, al seno de una coexistencia de derechos basados en la reciprocidad". (Ver Raymond Verdier, "Cheff [...]", 1965, p. 349). La conceptuación es muy clara y, aunque proviene de una investigación sobre el Africa, pienso que es semejante a mis hipótesis sobre el mundo precolombino.

58 Pease sugiere el término "donaciones de poder".

59 Cfr. supra, passim.

60 María Rostworowski, «Nuevos datos sobre tenencias de tierras reales en el incario», en: Revista del Museo Nacional, $N^{\circ}$ XXI, Lima, 1962. 


\section{La yuxtaposición de los sistemas}

«La determinación de la "propiedad conocida de los indios" fue el problema más espinoso que tuvieron los españoles para darle una «solución justa" $y$ acorde con el pensamiento cristiano", ${ }^{61}$ pues se enfrentaron dos sistemas distintos que se fueron yuxtaponiendo en el tiempo. Como señaláramos más arriba, Matienzo ${ }^{62}$ fue el primero en opinar acerca de parcelar las «tierras del común»; la cuestión era la adecuación de los sistemas.

Ots Capdequí ${ }^{63}$ nos describe,

"[...] quedaba solo como verdadero problema el de la población india, a la cual no podía sometérsele de un modo absoluto a nuestras propias leyes, y el que la ordenación de aquellas cuestiones que la conquista y colonización de tierras que constituían un mundo nuevo, plateasen por primera vez. De aquí el carácter casuista de nuestra legislación de Indias".

Conforme refiere Mariluz Urquijo, ${ }^{64}$ en fecha tan temprana como 1513, el requerimiento que los conquistadores españoles leían a los indios al tomar posesión de las tierras en nombre del Rey, prometía «os dejaremos vuestras [...] haciendas libres y sin servidumbrem. Asimismo, con anterioridad, en una Instrucción del veinte de marzo de $1503,{ }^{65}$ se limitaba la facultad de alienabilidad de la tierra para los indios, para evitar abusos y en claro entendimiento que ellos no comprendían el significado de la compraventa y, por tanto, de la propiedad.

61 Polo de Ondegardo, «Relación de los fundamentos[...]», op. cit., p. 70 y ss.

62 Este deriva de la discusión Las Casas/Sepúlveda sobre el carácter de los indios: ¡̇se podían vender? ¿eran cosas? ¿eran humanos? Esto último se resolvió con una Bula del Papado - el carácter humano de los indios- (Paulo III en 1537). La Corona, en 1520 determinó que los indios eran libres y libremente debían ser traídos a la fe de Cristo. Se reafirmó en 1534 y, finalmente en 1542 con las Leyes Nuevas, donde triunfa las tesis lascasianas: la infidelidad no priva de los derechos.

63 Cfr. Supra.

64 José María Ots Capdequí, El derecho de propiedad en nuestra legislación de Indias, Minerva, Bogotá, 1940, p. 6.

65 José María Mariluz Urquijo, El régimen de la tierra en el derecho indiano, Perrot, Buenos Aires, 1978, p. 24. 
Por otra parte la Recopilación de las Leyes de Indias indica (Ley No 18, Título12, Libro 4) ${ }^{66}$

"[...] que a los indios se les dejen tierras [...] con sobre todas las que le pertenecieren, así, en particular, como por sus comunidades, y las aguas, y riegos"

Pero la formación de los dominios territoriales nació fundamentalmente de las mercedes de tierras. ${ }^{67}$ En estas se incluían cláusulas del siguiente tenor:

«[...] la cual dicha merced le hacía e hizo siendo sin perjuicio de naturales y siendo con perjuicio sea visto no serle hecha dicha merced". ${ }^{68}$

Esas mercedes, que originariamente otorgaban los conquistadores y los Cabildos, entraron bajo el control de la Corona, siguiendo la doctrina de las Regalías que enunciara claramente Solórzano y Pereira, ${ }^{69}$ para aquello que hoy llamaríamos el subsuelo y que lo extendió a los bienes mostrencos y vacantes.

El control de la Corona podemos apreciarlo en dos instituciones fundamentales: la composición y la confirmación. Por Real Cédula de $1591^{70}$ se reafirmó el derecho de la Corona para otorgar tierras, estando obligados los ocupantes a exhibir los justos títulos de las mismas. Careciéndose de los mismos o estando incompletos, se podían "componer" mediante un pago a la Corona. ${ }^{71} \mathrm{El}$ rigor de estas disposiciones fue atenuado para la

66 José María Ots Capdequí, El derecho de [...], op. cit., p.116.

67 Leyes de Indias, Recopilación de Leyes de los Reynos de Indias, Edición facsimilar, [1681], Ediciones de la Cultura Hispánica, Madrid, 1973.

68 José María Ots Capdequí, Manual de historia del Derecho Español en las Indias, Instituto de Historia del Derecho argentino, Buenos Aires, 1943, p. 14 y ss.

69 El autor toma como ejemplo la merced concedida por el Gobernador del Tucumán, don Pedro de Mercado y Peñalosa a don Melián de Leguisamón en 1599.

70 Juan de Solórzano y Pereyra, Política indiana, Biblioteca de Autores Españoles, Madrid, [1642], 1972, p. 303.

71 Gazpare Escalona y Agüero, Gazophilacium Regium Publicum, Edición facsimilar, $1775,207 / 212$. 
población indígena por orden del virrey García Hurtado de Mendoza, ${ }^{72}$ nuevamente en una clara tendencia a separar uno y otro dominio. ${ }^{73}$

La confirmación, por otra parte, era el requisito formal para adquirir el pleno dominio. ${ }^{74}$ Si bien en teoría debía ser otorgada por el Rey, en la práctica se prescindió de ese requisito, saneándose los títulos solamente por vía de la composición. ${ }^{75}$

Podemos establecer un mecanismo de articulación de los dos sistemas a través de la autoridad. Tanto en el caso precolombino como en el mundo colonial, es la autoridad quien decide la «adquisición» de la propiedad, en este caso inmueble. No estamos frente a un derecho abstracto, claro y nítido.

Aún las mercedes otorgadas legítimamente, con títulos saneados, conllevaban el requisito de residencia y, sobre todo, de cultivo. A mi entender no existía un sentido «patrimonial de la tierra» claro y definido. Eso ha llevado a algunos autores a referirse como «oferta ilimitada de tierra ${ }^{76}$ y la formación de un "feudalismo americano»." ${ }^{77}$

«En el contexto americano la tierra no tiene precio, porque no tiene valor. Lo que tiene «valor» no es la tierra, sino el edificio, las plantas, los trabajos de irrigación, las herramientas y -especialmente- la masa de trabajadores atados a la tierram. ${ }^{78}$

72 José María Ots Capdequí, Manual de [...], op. cit., p. 20 y ss.

73 Cuarto Marqués de Cañete, Virrey del Perú (1590-1596).

74 Gazpare Escalona y Agüero, Gazophilacium [...], op. cit., 212/215.

75 José María Ots Capdequí, Manual de [...], op. cit., p. 25 y ss.; Antonio de León Pinelo, Tratado de las confirmaciones reales, [1630], Buenos Aires, 1922 y Antonio de León Pinelo, Tratado de las confirmaciones reales, Buenos Aires, 1967.

76 En la actualidad, el Gobierno ha creado un Registro de la Propiedad Predial a fin de sanear los títulos de propiedad en los terrenos invadidos y/o con problemas de titulación. Estos surgen muchas veces de urbanizaciones que no han completado los trámites respectivos en su oportunidad. Para mí es una versión moderna de la composición colonial. Definitivamente será una generación de conflictos, toda vez que se trata de un Registro paralelo al catastro oficial del Registro de la Propiedad Inmueble.

77 Ruggiero Romano, "Acerca de la "oferta ilimitada» de tierras: a propósito de América Central y Meridional», en: Flores Galindo y Plaza (Eds.), 1975.

78 Ruggiero Romano, "Entre la encomienda castellana y encomienda indiana: una vez más el problema del feudalismo americano", en: Anuario del Instituto de Estudios Histórico Sociales, 1992a, 3, Tandil. Reproducido en Romano (1992), 1988. 
La formación de un auténtico mercado de tierras, donde se negocian derechos de propiedad estuvo sin duda ausente y la figura se repitió, como se verá, en la etapa republicana. Llámese "feudalismo americano" o "yuxtaposición de sistemas", como he mencionado, resulta claro que la noción abstracta de propiedad, inexistente en el mundo precolombino, se vio afectada por la imposición de un sistema basado en la propiedad, al menos teóricamente, pero que en la práctica dependía del poder. En ese sentido hubo una suerte de continuidad que permitió el ajuste y la «acomodación» entre los dos mundos.

\section{Legislación y ejemplos del Perú republicano}

\subsection{De la Independencia al Código Civil de 1852}

En el mundo independentista de comienzos del siglo XIX, América se vio influida por el pensamiento liberal, al menos en las formas.

Comencemos por el Decreto de Simón Bolívar del 8 de abril de 1824, ${ }^{79}$ que en sus considerandos señala:

"Que a pesar [...] nunca se ha verificado la repartición de tierras con la proporción debida"

"Que la mayor parte de los naturales han carecido del goce y posesión de ellas"

"Que mucha de las tierras aplicables a los llamados indios se hallan usurpadas por varios pretextos por caciques y recaudadores"

"Que el uso precario que les concedió el Gobierno Español»

«Que la Constitución de la República no reconoce la autoridad de los caciques sino de los intendentes»

Estamos frente al problema que indicara Matienzo: no hay una clara especificidad del derecho de propiedad en el caso de la población indígena. Se mencionan categorías como goce, posesión y uso precario, para una institucionalidad ancestral y después de más de tres siglos de gobierno colonial.

79 Ruggiero Romano, «Entre la encomienda [...]», op. cit., p. 19. 
Se denota, además, un desconocimiento de la asignación periódica de tierras y, sobre todo, se hace hincapié en la autoridad que ejecuta la misma, asimilándola a la usurpación; aún cuando en muchos casos esto fuera así, no puede generalizarse $y$, antes bien, se trataba de imponer un sistema.

En el artículo $2^{\circ}$ del acotado se indica:

«En la masa repartible se incluirán aquellas de ques han aprovechado los caciques y recaudadores por razón de su oficio [...]»

Por consiguiente,

"Resulta bastante obvio, independientemente de los abusos innegables, que existía una masa repartible, es decir tierra sin cultivar; sabemos que esto era parte del sistema rotativo de cultivos y de la siembra en distintos pisos ecológicos, pero que nuestros predecesores no lo entendían, o no querían entender. ¿Qué es eso de masa repartible? ¿Sobraba tierra?. Este es un punto muy importante que se repetirá de tiempo en tiempo en la legislación analizada, evidenciando, para mí, una dualidad de comportamiento del Estado [... ${ }^{80}{ }^{80}$

Esa dualidad, típica del mundo andino, dejando áreas indefinidas, $b u$ ffer-zones, como las he denominado, ${ }^{81}$ en el caso del derecho de propiedad se reflejan en la ambigüedad de la institución e indican una pauta de comportamiento en la solución de conflictos: la falta de precisión obliga a una permanente negociación y ese es el espacio de la autoridad.

El citado Decreto y sus sucesivas reiteraciones no llegaron a cumplirse, por resistencia de los caciques y la propia población indígena, debiendo suspender el Congreso, en 1827, la ejecución de las ventas y reconociendo a los indígenas el "pleno dominio de las tierras» por Resolución Legislativa del 31 de marzo de $1828,{ }^{82}$ la misma que fue ratificada por el Congreso en $1893 .^{83}$

80 Juan Oviedo (Ed.), Colección de Leyes, Decretos y Ordenes publicadas en el Perú desde el año 1821 hasta el 31 de diciembre de 1859, Lima, 1861-70.

81 Héctor Omar Noejovich, "Las relaciones del [...]”, op .cit., pp.48 y 49 .

82 Héctor Omar Noejovich, "El pensamiento dual [...]”, op. cit. y Los albores [...], op. cit.

83 Héctor Omar Noejovich, «Las relaciones [...]», op. cit., p. 49. 
Durante el interregno que representó la Confederación Peruano-Boliviana, entre 1836-39, se sancionó el Código Civil de Santa Cruz de 1836. ${ }^{84}$ Su artículo $299^{\circ}$ muestra una faceta interesante:

«Bienes comunes son aquellos a cuya propiedad y producto tienen un derecho adquirido los habitantes de una o muchas comunidades»

Resumamos algunos rasgos:

(a) Existen bienes comunes, no sujetos a las reglas del condominio y/o copropiedad. No hay lugar a la parcelación ni a la división.

(b) Existen derechos de varios sujetos, tanto a la propiedad como a su producto; distintas formas que se integran en una unidad.

(c) Existe pluralidad de sujetos comunitarios con derecho a una misma tierra, con clara alusión a la institución de los mitmaqkuna.

Sin discutir la inspiración francesa del acotado, nos parece que este artículo intentó integrar jurídicamente el sistema ancestral dentro de un marco institucional moderno, si bien no establece las reglas al interior de las comunidades. ${ }^{85}$ Contemporáneo es el Proyecto del Código Civil de $1835,{ }^{86}$ conocido como el Proyecto Vidaurre. Aquí es el modo de adquisición el aspecto central, fundamentando:

«El principio de adquirir en el estado natural, era la ocupación; el título de fuerza». ${ }^{87}$

Bajo esa tesitura se proyectó el siguiente articulado:

Art. $1^{\circ}$.- Todo lo que no es poseído por otro, si se ocupa, es capaz de ocuparse y se manifiesta el ánimo de retenerlo, nos corresponde de pleno dominio.

84 Ibid, p. 58.

85 Códigos, Código Civil Santa-Cruz del Estado Nor-Peruano, Imprenta de José Masías, Lima, 1836.

86 Héctor Omar Noejovich, «Las relaciones [...]», op. cit., p. 51.

87 M. L. Vidaurre, Proyecto de Código Civil Peruano, Imprenta del constitucional Justo León, Lima, 1835. 
Art. $2^{\circ}$.- $\mathrm{El}$ ánimo de retener lo que se originalmente se ocupa, es demostrado por el uso continuo y el trabajo.

Art. $17^{\circ}$.- El que quiera trabajar en suelo ajeno, cuyo dueño se ignora, plantando o edificando, denúncielo por desamparado $[\ldots]{ }^{88}$

Aquí la preocupación fue dar preeminencia a la ocupación como modo de adquisición. El denuncio y la posterior composición por las autoridades era la doctrina de la época. Así, legislativamente se reconocen ocupaciones en la villa de Sullana, en 1839 y en Ambo en 1842, a favor de las poblaciones indígenas. ${ }^{89}$ El poder administrador se transforma en adjudicatario de tierras. Esta política queda ratificada por Ley Ocupación de Tierras ${ }^{90}$ del 24 de mayo de 1845 (L.R.L. 72), la misma que luego fuera prorrogada cada veinte años. ${ }^{91}$

\subsection{Del Código Civil de 1852 al Código Civil de 1933}

A decir de Basadre, ${ }^{92}$ el Código Civil de 1852 es más bien una recopilación de leyes, antes que una institucionalización efectiva. Este modificó el temperamento del Código de Santa Cruz de $1836,{ }^{93}$ señalando:

«Art. $459^{\circ}$.- [...] son comunes las que pertenecen colectivamente a una corporación legalmente reconocida"

Las comunidades indígenas no fueron legalmente reconocidas sino hasta la Constitución de 1920 y recién incorporadas como sujeto de derecho privado en el Código Civil de 1936. El dispositivo fue ilusorio, como así también la adquisición por ocupación. En efecto, el acotado indicaba también:

88 Ibid., II, p. 10

89 M. L. Vidaurre, Proyecto [...], op.cit., pp. 5 y 6.

90 Para el caso de Sullana ver C.L.D.O, VI, 469, N³11; en los otros casos en Juan Oviedo, Colección [...], 1861-70, IV: pp. 141 y 298. En Huarochirí el Poder Ejecutivo por decreto devuelve tierras indígenas ocupadas por el Municipio.

91 L.R.L., Leyes y Resoluciones dictadas por la Legislatura, Edición oficial Belaunde, 1860 , p. 65.

92 Héctor Omar Noejovich, "Las relaciones [...]", op. cit., p. 53.

93 Jorge Basadre, Historia del Derecho peruano, 2ª Edición, Lima, 1985. 
"Art. $480^{\circ}$.- El que, por ocupación quiera hacer suya una cosa inmueble que no tiene dueño, se arreglará a lo prescrito en el Código de Enjuiciamiento sobre aplicación de bienes mostrencos.»

Pero a su vez la exposición de motivos de este articulado indicaba: «[...] son las leyes administrativas las que deben reglar esa adjudicación [...] ${ }^{94}$ Nuevamente inoperante el sistema judicial y la normatividad del derecho de propiedad a cargo del poder administrador.

Uno de los pocos ejemplos que encontramos, donde el Poder Ejecutivo deja en manos del Poder Judicial, es un conflicto en la asignación de tierras, en la Provincia de Acomayo, Departamento del Cusco, como se aprecia de una Resolución Suprema del 20 de octubre de $1876^{95}$ ordenando a los Prefectos y Municipios abstenerse de intervenir, salvo en caso de desórdenes. Pero recién en el siglo XX las comunidades fueron aceptadas como sujetos de derecho.

Siguiendo a Basadre ${ }^{96}$ estamos frente a una lucha por la propiedad privada mediante la libre enajenación como nos muestra el siguiente articulado:

"Art. 1194\%.- Ninguno puede vincular bienes en el Perú ni fundar capellanías; todas las propiedades son enajenables»

Si bien ello fue previsto para la desamortización de bienes de la Iglesia y la disolución de los mayorazgos, se presenta también opuesto a las "propiedades indígenas", toda vez que se tratan de bienes claramente vinculados y con restricciones a su alienabilidad, a través de disposiciones paralelas nacidas del poder administrador. Nuevamente enfrentamos la contradicción entre instituciones de iure e instituciones de facto.

Como bien señala Luna Victoria: ${ }^{97}$

94 Códigos, Código Civil [...], op. cit.

95 Miguel Antonio Lama y Goytizolo (Eds.), [1852], Código Civil concordado, Imprenta Gil, Lima, 1914.

96 Manuel Vicente Villarán, Páginas escogidas, Lima, 1962.

97 Jorge Basadre, "Contribución al estudio del derecho anterior al Código Civil de 1952", en: García Rada, Derecho, 1963, p. 36. 
«[...] El tema del indio no puede ser entendido sin comprender el rol de la tierra. La vinculación del indio con la tierra, desde la organización del imperio incaico, fue política antes que jurídica [...].»

Respecto de esta última afirmación nos remitimos a nuestras propias conclusiones. ${ }^{98}$ Sin embargo, coincidimos con el autor citado ${ }^{99}$ y siempre con referencia al Código Civil de 1852

"[...] la comunidad indígena no llegó a ser comprendida como una realidad económica y jurídica, sino como una forma colectiva de propiedad, que era necesario abolir junto con las demás vinculaciones precisamente para promover la adjudicación y disposición individual de parcelas $[. .$.$] ».$

Tal como indicáramos anteriormente, no obstante la prórroga de la Ley de Ocupación de Tierras del 14 de mayo de $1845,{ }^{100}$ el 11 de octubre de 1893, el Congreso aprueba una Resolución que renueva un pensamiento doctrinario:

«El Congreso ha resuelto declarar los indígenas del distrito de Cabana, en la Provincia de Lucanas, así como todos los demás de la República, son legítimos propietarios de los terrenos que actualmente poseen en virtud de las leyes de 1824 y demás de la materia [...]».

Quedó vigente, sin embargo, la suspensión ordenada en 1827 respecto de las ventas y parcelación de las tierras indígenas. ${ }^{101}$ Una vez más, aquello que la «ley se obedece pero no se cumple». ${ }^{102}$ Se reafirmaron los principios bolivarianos acerca que los propietarios son los indios y no las comunidades, pero se mantuvo el status quo en materia de derecho privado: las comunidades recién fueron incorporadas como titulares a través del Art. $70^{\circ}$ y siguientes del Código Civil de 1936.

98 César Luna Victoria, "Código Civil de 1852: lo nacional y lo importado", en: Derecho $\mathrm{N}^{\circ}$ 42, Fondo Editorial PUC, Lima, Diciembre, 1988, p. 84.

99 Cfr. supra, II.

100 Ibid, p. 84.

101 Ricardo Aranda (Ed.), Leyes y Resoluciones de carácter y local expedidas por los Congresos Ordinarios y Extraordinarios, Imprenta Universo, Lima, 1878-1993, p. 92.

102 Cfr. Supra. 


\subsection{Ejemplos contemporáneos}

La invasión de tierras en Lima tiene una larga tradición, especialmente por las grandes migraciones desde la década de los años sesenta. A decir de Dietz, ${ }^{103}$ a pesar de las sanciones, tienen una larga y casi «honorable historia». Durante la alcaldía socialista 1980-83, la Municipalidad de Lima otorgó «títulos de propiedad» en terrenos estatales invadidos. Una de las condiciones era habitar los mismos, bajo pena de revertirse al municipio.

En sus considerandos, cada título señalaba «en armonía con los criterios señalados por los ministerios de Justicia y Vivienda". Esa «armonía" carecía de sustento legal alguno y, además, eran imposibles de inscribir en los Registros Públicos. Por otra parte, violaban el ordenamiento legal vigente que exige escritura pública para la constitución y/o transmisión de derechos reales sobre inmuebles. ${ }^{104}$

He hecho hincapié en la existencia de una alcaldía socialista, ${ }^{105}$ porque una explicación era el rechazo al «ordenamiento jurídico burgués». Pero a la luz de la temática que venimos desarrollando, cabe muy bien esa actitud como una forma ambigua de interpretar el derecho de propiedad.

Otro caso de invasión nos muestra una faceta judicial de esa noción. El 8 de noviembre de 1984, XX interpone una acción de reivindicación contra una Asociación Pro-Vivienda (forma eufemística en la que se esconden los «invasores profesionales de tierras»). La Corte Suprema, el 2 de septiembre de $1991,{ }^{106}$ confirmó los fallos de las instancias anteriores a favor de los demandantes. En el ínterin, obviamente, los invasores fueron levantando construcciones. El 12 de abril de 1999 el Juez ordena el desalojo en los siguientes términos: «entiéndase la diligencia sobre la superficie de metros cuadrados precisados, no respecto de las fábricas construidas». ${ }^{107}$ Apelado el auto, la Corte Superior lo confirmó el 3 de marzo de 2001. ${ }^{108}$

103 Para una excelente discusión sobre este adagio jurídico ver Tau Anzoategui, La ley [...],1996, p. 69 y ss)

104 Henry Dietz, Land Invasion and Consolidation: $A$ study of workin poor/ governmental relations in Lima, Perú. Institute of Latin American Studies, 195 off print series; University of Texas at Austin, 1977, p. 378.

105 Nora Olivero, «Derecho Precolombino y Derecho Indiano", en: Derecho $N^{\circ} 42$, Fondo Editorial PUC, Lima, Diciembre, 1988.

106 Algunos de los regidores eran más bien de la ultra izquierda.

107 Expediente $N^{\circ} 309-89$. 
Por supuesto que es contrario tanto a la doctrina jurídica como a la legislación vigente, ${ }^{109}$ pero evidencia un comportamiento respecto del derecho de propiedad. ${ }^{110}$ En efecto, tanto el juez que emitió esa resolución, como los vocales que la confirmaron, no ignoran la accesión, sino que no hacen suya la noción abstracta de propiedad en forma completa, limitándose a los formalismos procesales.

\section{Reflexiones finales}

Existe una herencia ancestral donde la noción de propiedad era inexistente. Producido el «encuentro de dos mundos» se yuxtaponen los sistemas jurídicos, en una suerte de mestizaje que perdura hasta nuestros días. $Y$ ya no solamente es el problema de la tierra, sino que también se extiende a los derechos intelectuales. ${ }^{111}$

Ello genera, desde el ángulo institucional, una sensación de precariedad del derecho de propiedad mismo. No se trata solamente de un problema de las comunidades sino de una percepción «difusa» del derecho de propiedad, como consecuencia de ese "mestizaje». ${ }^{112}$

108 Expediente $N^{\circ} 23841-1996,52^{\circ}$ Juzgado Colectivo Civil de Lima. Se omiten los nombres de las partes por razones obvias. dos.

109 Expediente $\mathrm{N}^{\circ}$ 6207-2000, Sala de Procedimientos de Conocimiento y Abrevia-

110 Lo edificado en terreno ajeno es propiedad del dueño del terreno por accesión. El Código Civil del Perú lo contempla en su artículo 943․

111 Conocemos casos donde se vendió la casa más no el terreno.

112 La piratería de software, CD y libros es "socialmente aceptada", no siendo objeto de una represión seria y profunda por parte de las autoridades.

113 Otro ejemplo moderno son los conflictos sobre las "Asociaciones" que construyeron en las playas del sur. Ya no se trata de comunidades indígenas, sino de clases sociales suficientemente educadas. 


\section{Bibliografía anexa}

Fuentes y documentos impresos:

Urteaga, Horacio y Romero, Carlos (Eds.). Colección de libros y documentos para la historia del Perú. 6 vol, $1^{2}$ serie, Lima, 1916/17.

Fuentes de legislación:

C.L.DO., Colección de Leyes, Decretos y Ordenes publicadas en el Perú desde su Independencia, Imprenta de José Masías. Tomos I a VII. Lima, 1830-42.

Colección de Leyes, Decretos y Ordenes publicadas en el Perú desde su Independencia, Imprenta de José Masías. Tomos VIII al XII. Lima, 1852-53.

Código Civil. Lima: Edición oficial, 1936.

L. y D., Leyes y Decretos. 1868-1873. Edición oficial, 1873.

Leyes y Decretos. 1874-1876. Edición oficial, 1876.

Nieto, Juan Crisóstomo (Ed.). Colección de Leyes, Decretos y Resoluciones expedidos en el Perú desde principios de su independencia. Lima, 1864.

Obras citadas:

Flores Galindo, Alberto y Plaza, Orlando (Eds.). Haciendas y plantaciones en el Perú, PUC, Facultad de Ciencias Sociales, Lima, Mimeo, 1975.

Masuda, Sosho (Ed.). Etnografia e Historia del mundo andino. Continuidad y Cambio, Universidad de Tokio, Japón, 1986.

Millones, Luis y Tomoeda. El hombre y su ambiente en los Andes centrales, Hiroyasu (Eds.), Serie Ethnological Studies, 10, Osaka, 1982.

Nicolini, Ugo. "Droit de propriété absolue et demembrant de la propriétén en : Actes du Vème Congrès Internacionale de Droit Compare, Bruselas, 1958. 